\title{
Smart health care opportunities and challenges, by using sustainable efficiency big data analysis
}

\author{
1 Abdelkhalek I. Alastal, 2Muain Qasem Jawabrah, 3Read A. Salha and 4Usama Ibrahim Badawy
}

\author{
1Resarcher by the Geography and GIS Department, Arts College, Islamic University of Gaza, \\ Palestine \\ 2Assistant professor of Architecture, at the Engineering Department of Birzeit University \\ 3Assoiat professor of Geography and GIS Department, Arts College, Islamic University of Gaza, \\ Palestine
}

4Former Professor of Architecture, at the Engineering Department of Birzeit University, currently by

the UN.

\begin{abstract}
Regarding the progress to the computerized economy, the pace at which new technologies and advances are transforming the healthcare sector has accelerated. Where healthcare big data analytics is emerging on a promising horizon for gaining insights from very large amounts of data to improve results while diminishing expenses through the new development potential. The purpose of big data analytics in healthcare is to promote healthy living and prosperity for all people everywhere and at all ages.

This study aims to examine the potential and contribution of big data analytics in healthcare by examining and reviewing the scientific research literature on the concept and foundations of big data. This includes important potential scenarios for the application of big data analysis in healthcare. In addition, the important steps are for the health organization to turn into a data-driven health organization and for health care to become a smarter organization. Furthermore, exploring the challenges that big data in healthcare is facing and its benefits. Hence, this study provides a useful reference point for researchers to review the major emerging big data technologies.
\end{abstract}

Keywords: Big data technology, Data analytics, Smart healthcare, stakeholders, sustainability

\section{INTRODUCTION}

With the power of telecommunications and the internet, big data becoming a growing force changing healthcare landscape. New technology, improved connectivity and mobility make it possible to combine different and widely used data sources into a combined "data lake". This offers enormous potential for health organizations that can now collect, share, integrate and analyze data from all relevant stakeholders and achieve the goals of intelligent health care.

The healthcare system generated large amounts data, driven by record keeping, compliance and regulatory requirements, and patient care [1].

Big data in healthcare massive, not only because of its volume but also because of the diversity data types and the speed which must be managed [2].

Entirety data in healthcare and patient well-being makes up the big data in the healthcare system. involving clinical data and systems to support clinical decisions (doctor's written notes and prescriptions, medical imaging, laboratory, pharmacy, insurance and other administrative data), patient data in electronic patient records, emergency data, machine-generated data / sensor data. In addition, monitoring vital signs, social media posts, websites, and articles in medical journals.

In big data scientist, among enormous amount and variety data there is big opportunity to improve quality of healthcare. By recognizing relations and understanding patterns and trends in the data, big data analysis can improve care, save lives, and lessen costs. As a result, big data analytics applications in healthcare are utilizing the explosion of data to produce insights to make better aware decisions [3-5]. At the point when big data is collected and analyzed patterns and trends exposed, healthcare providers and other health system actors can develop more thorough and insightful diagnoses and treatments, leading to higher quality care at lower costs and better overall results [5].

This study presents general review of big data analytics in healthcare, and explore how is turning into growing force in the changing healthcare landscape. By harnessing power of telecommunications and Internet delivering big data to healthcare. Also explains why is significant healthcare organizations be data-driven, defines and discusses the various challenges and benefits of using big data analytics, sources, types, and tools of big data in healthcare. In addition, possible scenarios application big data analyzes healthcare are presented. Finally, we offer recommendations and conclusions to help health care become smarter and more efficient. 


\section{LITERATURE SURVEY}

In fact, we find that using advanced technology in big data analytics is developing exponentially continuously, requires effective analytical techniques to analyze unknown useful facts, patterns, relations and new trends that provide a new way to treat disease to deliver good healthcare at low cost for everyone.

Source [6] provided overview of big data analytics in healthcare systems. Additionally, described big data generated by these systems, data characteristics, and how big data analytics assists to obtain a meaningful insight on these data set.

Source [7] highlighting the big data analytics in medicine and healthcare. Study covered integration and analysis of large amount complex heterogeneous data, such various omics data (genomics, transcriptomics, proteomics, metabolomics, pharmacogenomics), biomedical data and electronic health records data. Addition, underlined the challenging issues about big data privacy and security.

The results of study of source [8] revealed importance questions like - what about using electronic health records? how to store and use electronic health records, why storage, and use can promote nurses' meaningful use of big data analytics with EHRs. This study explored the appropriate adaptation of analytical tools to EHRs from the different knowledge mode in order to shape meaningful use big data analytics with EHRs.

The study in source [9] have presented different analytical possibilities exist in patient-centric healthcare system from the perspective different interest group. In addition, various big data frameworks were checked with regard to underlying data sources, analysis functions and application areas. In addition, the importance big data tools in developing healthcare ecosystem is presented.

Study in source [10] specified huge shortage of proper health facilities and addressed how to provide greater access primary health services in rural India. In addition, critical computational analytical capabilities big data when processing large amount transactional data in real time situations. The aim of this study was introduced reforms the healthcare sector and promote discussions about how the government can harness innovations in big data analytics to improve the rural healthcare system.

\section{DEFINITION OF BIG DATA IN HEALTHCARE}

Actually, there are numerous definitions that researchers have provided for big data [11-12], anyway no sole meaning definition of big data is commonly known [13]. Definitions differ depending on the specializations, purposes, and aspects dealt with. Where the big data in healthcare includes gathering huge assortments of data from different healthcare foundations followed by storing, managing, analyzing, visualizing, and delivering information for effective decision-making. Table $\mathbf{1}$. summarize most important big data definitions in healthcare.
Table 1. Basic definitions of big data analytics in

healthcare

\begin{tabular}{l|l} 
Source & Definition \\
\hline \multirow{3}{*}{ Source } & \begin{tabular}{l} 
Definition of European commission: big \\
data in health includes high volume, high \\
diversity clinical, \\
environmental, and lifestyle information \\
collected from single individuals to large \\
cohorts, in relation to their health and \\
wellness status, at one or several time \\
points. There are six characteristics \\
regarding big data in healthcare, they are, \\
volume, variety, velocity, veracity, \\
variability, and value. \\
\hline Big data in health refers to large regularly \\
or automatically gathered datasets, which \\
are electronically captured and stored. It is \\
reusable in the meaning of multipurpose \\
data and include the fusion and relation of \\
existing databases for the purpose of \\
improving health and health system \\
performance. It doesn't indicate to data \\
collected for a particular study.
\end{tabular} \\
\hline In healthcare, big data involves patient- \\
related data from electronic health records, \\
computerized physician order entry \\
systems, clinical decision support systems, \\
medical devices and sensors and research \\
articles. This data is huge because of its \\
volume, diversity of data types and speed \\
at which it must be analyzed, which makes \\
it difficult for traditional software and \\
hardware to deal with it.
\end{tabular}

So we note that there are differences between the previous definitions, but by integrating these and other definitions we can currently achieve a more comprehensive definition as the definitions change depending on requirements, new technologies and future developments, the definition must be comprehensive so that we have smart healthcare.

\section{SOURCES, TYPES AND TOOLS OF BIG DATA IN SMART HEALTHCARE [17- 19]}

Into smart health care, it can be observed that there are many terms, including digital health, health information technology, e-health, m-health, health 2.0, e-medicine, telemedicine, associated with the collection, analysis and analysis are applications of big data in healthcare. Below are the main sources, types, and tools for big data in healthcare.

1. Web and social media data: click stream and interaction data from Face book, Twitter, LinkedIn, blogs, and the like. It can likewise involve health plan websites, smart phone apps and so on.

2. Machine to machine data: readings from remote sensors, meters, and other vital sign devices. 
3. Big transaction data: health care claims and other billing records increasingly available in semi-structured and unstructured formats.

4. Biometric data: genetics, handwriting, retinal scans, $\mathrm{x}-$ ray, finger prints and other medical images, blood pressure, pulse and pulse oximetry readings, and other similar types of data.

5. Human-produced data: unstructured and semistructured data such as EMRs, doctor's notes, email, and paper documents.

Health data from different sources must be linked, this data is collected and stored in the form of raw data that has to be processed, see Figure 1., at this point, several options are obtainable. A service oriented architectural approach joined with web services is one probability. The data stays raw and services are utilized to call, retrieve and process the data for tools which use in big data. Another approach is data warehousing where in data from different sources is collected and prepared for handling, in spite of the fact that the data is not available in real time. Due to the continuous technology development, it is clear that considered possible data sources for big data are constantly evolving. Therefore, the list presented cannot be complete.

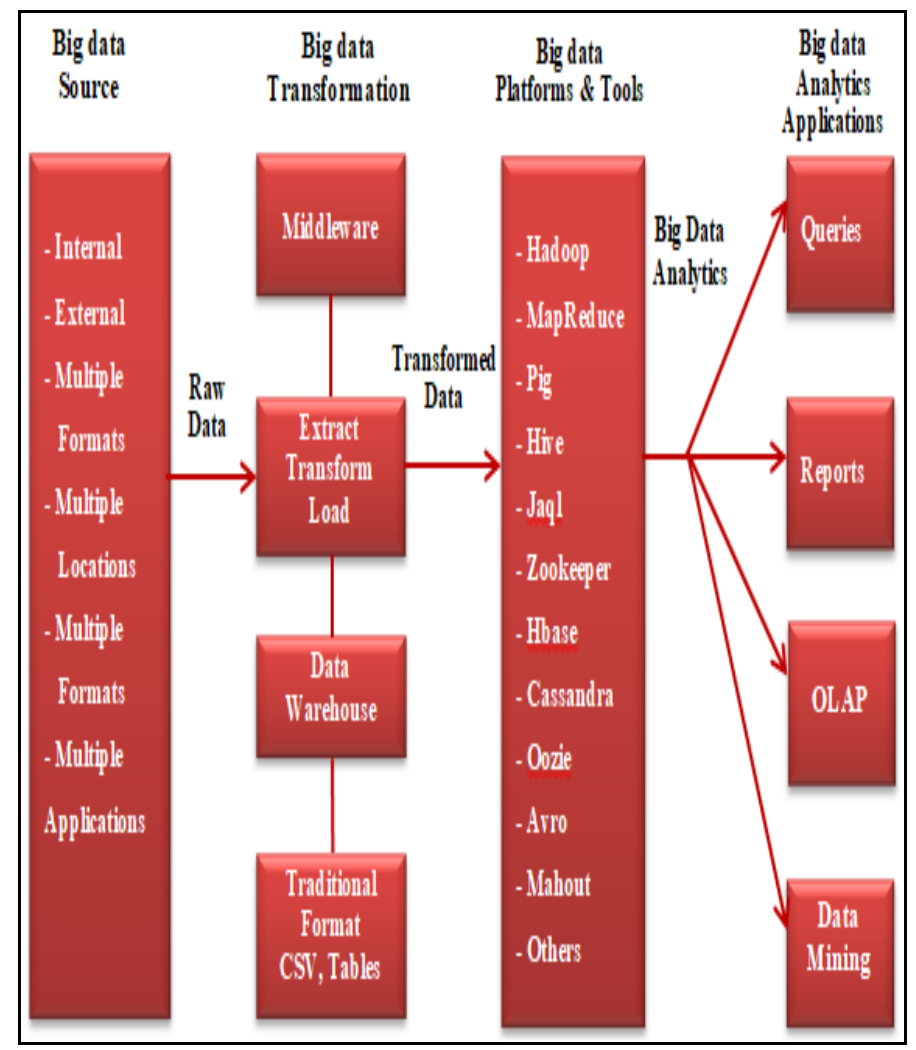

Figure 1. Big data in smart healthcare: sources, tools, analytics and application.

\section{Source: 35}

Moreover, the combination of data sets produces another level of complexity, yet also creates additional opportunities. This is the reason that the concept of data fusion is gaining significance. As well the tools which used in analyzing the big data have been developing in terms of number, performance and capabilities. Table 2. summarize some of the tools support big data analytics in smart health care.

Table 2. Some of the tools supporting big data analytics in smart health care.

\begin{tabular}{|c|c|}
\hline Platform/Tool & Description \\
\hline $\begin{array}{l}\text { The Hadoop } \\
\text { Distributed File } \\
\text { System (HDFS) }\end{array}$ & $\begin{array}{l}\text { Empowers the underlying storage } \\
\text { for the Hadoop cluster. It partitions } \\
\text { the data into smaller parts and } \\
\text { distributes it over the different } \\
\text { servers/nodes. }\end{array}$ \\
\hline MapReduce & $\begin{array}{l}\text { Gives the interface for the } \\
\text { distribution of sub-tasks and the } \\
\text { aggregating of outputs. At the } \\
\text { point when tasks are executed, } \\
\text { MapReduce tracks the processing } \\
\text { of each server/node. }\end{array}$ \\
\hline $\begin{array}{l}\text { PIG and PIG } \\
\text { Latin } \\
\text { (Pig and } \\
\text { PigLatin) }\end{array}$ & $\begin{array}{l}\text { Pig programming language is } \\
\text { designed to absorb all types of data } \\
\text { (structured/unstructured, and semi } \\
\text { structured). It is included of two } \\
\text { key modules: the language itself, } \\
\text { called PigLatin, and the runtime } \\
\text { version in which the PigLatin code } \\
\text { is executed. }\end{array}$ \\
\hline Hive & $\begin{array}{l}\text { Is a runtime Hadoop propping } \\
\text { architecture that use Structure } \\
\text { Query Language (SQL) with the } \\
\text { Hadoop platform? It allows SQL } \\
\text { programmers to develop Hive } \\
\text { Query Language (HQL) statements } \\
\text { similar to typical SQL statements. }\end{array}$ \\
\hline Jaql & $\begin{array}{l}\text { Is a functional, declarative query } \\
\text { language intended to handle large } \\
\text { data sets. To simplify parallel } \\
\text { processing, Jaql transform high- } \\
\text { level queries into low-level queries } \\
\text { consisting of MapReduce tasks. }\end{array}$ \\
\hline Zookeeper & $\begin{array}{l}\text { permits a centralized infrastructure } \\
\text { with different services, giving } \\
\text { synchronization across a cluster of } \\
\text { servers. Big data analytics } \\
\text { applications use these services to } \\
\text { orchestrate parallel processing } \\
\text { across big clusters. }\end{array}$ \\
\hline HBase & $\begin{array}{l}\text { Is a column-oriented database } \\
\text { management system that sits on } \\
\text { head of HDFS. It utilizes a non- } \\
\text { SQL approach. }\end{array}$ \\
\hline
\end{tabular}




\begin{tabular}{|c|c|}
\hline Cassandra & $\begin{array}{l}\text { in addition to being a distributed } \\
\text { database system. It is specified as a } \\
\text { top-level project modeled to handle } \\
\text { big data distributed across many } \\
\text { utility servers. It also offers } \\
\text { trustworthy service with no } \\
\text { particular point of failure and it is a } \\
\text { NoSQL system. }\end{array}$ \\
\hline Oozie & $\begin{array}{l}\text { An open source project, regulates } \\
\text { the workflow and coordination } \\
\text { among the tasks. }\end{array}$ \\
\hline Lucene & $\begin{array}{l}\text { It's a project that is utilized widely } \\
\text { for text analytics/searches and has } \\
\text { been fused into different open } \\
\text { source projects. Its domain } \\
\text { involves full text indexing and } \\
\text { library search for use inside a Java } \\
\text { application. }\end{array}$ \\
\hline Avro & $\begin{array}{l}\text { Eases data serialization services. } \\
\text { Versioning and version control are } \\
\text { additional useful features. }\end{array}$ \\
\hline Mahout & $\begin{array}{l}\text { Is one more Apache project whose } \\
\text { objective is to create free } \\
\text { applications of distributed and } \\
\text { scalable machine learning } \\
\text { algorithms that support big data } \\
\text { analytics on the Hadoop platform. }\end{array}$ \\
\hline
\end{tabular}

\section{BENEFITS USING BIG DATA IN SMART HEALTHCARE}

By digitized, merged and effectively using big data, health organizations can achieve important benefits. By finding associations and understanding patterns and trends in data, big data can save lives, provide quality care at a lower cost, and accomplish better generally results. Applications can be either prospective data monitoring or retrospective data analysis and help to increase the effectiveness and quality of treatments [6, 20-27]:

\section{- Evidence-based medicine}

- Ingathering and analyzing a diversity of structured and unstructured data - Electronic Medical Records, financial and operational data, clinical data, and genomic data - to conforming treatments with outcomes, predicting patients at risk for disease or readmission, reducing medical errors and provide more efficient care and reducing cost.

- Implementing advanced analytics to patient profiles (e.g., segmentation and predictive modeling) to determine people who might profit from proactive care, reduced probability of adverse reactions to medicines or lifestyle changes.

- Utilizing historic data to customize health care by foreseeing and/or assessing developments or outcomes, such as which patients are in danger for medical complications or hospital-acquired illness.
- Determining remedies, programs and processes that are not giving verifiable benefits or are being excessively expensive, and afterward deciding how to replace them with more proficient and compelling alternatives.

- Implementing gene sequencing more efficiently and cost adequately to make genomic analysis a part of the regular medical care decision process and the rising patient healthcare record.

\section{- Smart healthcare and clinical analytics at real-time}

- Amassing and synthesizing patient clinical records and claims datasets in real-time to give data and services to third parties.

- Recognizing individual and population trends more speedily and accurately by developing and deploying portable applications that assist patients manage their care, find providers, and improve their health.

- Observing medical devices, including wearable's, to catch and analyze in real-time large volumes of quick moving data, for safety observing and negative event prediction.

- Predictive analysis in medical services, big data is also utilized in predictive analysis to recognize and address medical problems before they become an unmanageable issue. Healthcare professionals can decrease the risk and solve the issue with the information got from the big data.

\section{- Smart health care and payers}

- Analyzing patient characteristics and the cost to determine the most clinically effective and also costefficient diagnoses and remedies.

- Determining, foresee, and decreasing roguery by implementing advanced analytic systems for fraud detection and verifying the accuracy and consistency of claims.

- Analyzing massive quantities of guarantee demands quickly in the pre-adjudication phase to minimize fraud, waste and abuse.

- Building sustainability into a healthcare system by getting clinical, financial and operational data together to analyze resource utilization, productivity.

\section{- Public smart health}

- With new analytics tools by big data can get for the most effective results across large populations and give appraisals dependent on high quality of healthcare.

- Analyzing ailments patterns and following its diffusion and transmission to improve public health monitoring and speed reaction.

- Ameliorating data paradigms to better predict virus evolution, leading to more accurately targeted seasonal vaccines for example, picking the yearly flu strains.

- Transforming huge amounts of data into actionable information that can be utilized to determine needs, offer services, and foresee and prevent crises. 
- Big data as emerging technology promise in assisting organizations to address and assess data from EHRs, clinic equipment, telehealth devices, and home health monitors.

- The new medications and therapies can be evolved, and patients can get targeted treatments that may prove more effective.

- Big data additionally can be utilized to ameliorate population health management, the determine and measurement of more accurate quality measures, and treatment protocols for a wide range of chronic conditions, for example, diabetes.

- Administering population health by revealing weaknesses within patient populations during ailment diffusion or crises, and afterward taking protective action.

- Knowledge role: Knowledge rise a critical role in growing the organization's competitive advantage and financial performance. Effective knowledge of healthcare activities are not limited to improving the operational capabilities of current healthcare, but also lower the cost of providing care products and prevent potential medical errors.

\section{BIG DATA CHALLENGES IN SMART HEALTHCARE $(14,18-21,27)$}

In the smart health big data analytics scene, significant challenges continue to hamper the health care industry's ability to use big data effectively. To bring about the health care revolution that modern IT promises, legal, technical, and cultural / societal barriers must be overcome. The most important are listed below:

- Data fragmentation: The fragmentation, segregation of data between labs, hospital systems, financial IT systems and EHRs, are considerable snag to utilizing big data in health care.

- Standards: Dealing with the myriad of standards or lack thereof creates interoperability challenges.

- Data security and privacy: The insufficiency of basic data security requirements is a significant risk degradation patient and consumer confidence in the health care system, as well data privacy, from where sensitivity of medical records, thus, privacy must be guaranteed.

- Transparency: The openness and transparency is maybe the most significant component of the all entities using big data. Weakness or absence transparency induces an absence of trust, and trust is primary for future learning and the useful application of big data in smart health care.

- Interoperability: Incorporation of big data technologies with existing project solutions is extremely important. Data ingestion, data modeling, data visualization utilizing existing tools must be supported.

- Data ownership: responsibility of health data and Use are significant issues when conversation how to approach big data in health care and whom can be utilized these data and for what purposes.
- Access data: the need for open access to health care data for research purposes, and the need to develop a big data industry, capable of investing a growing amount of resources into innovations in smart health care.

- Lack of training: shortage in analytical skills and experience are the most important component hindering the launch of big data initiatives in the smart health care.

- Funding Shortage: Resources must be allocated at the national level, Also, lack of planning and governance concerning utilize big data analytics in hospital-wide electronic health records needs to be addressed.

- Complex legal landscape: Efforts to address big health data face a complex legal landscape that continues to confuse patients, healthcare providers, healthcare IT developers, and other stakeholders. This situation requires major efforts to provide legal protection to patients and other stakeholders.

These organizations need to encourage the sharing of information and experiences, have administrative and leadership teams committed to turn, and develop programs to evolve data and analytics skills in their organization. Advancing across the analytics continuum toward being a data-driven organization involves a shift in the type of technologies and systems includes in working with the data, as well as a development in the kind of business questions being asked. (see Figure 2. And Table 3.).

While most organizations adopt a step-by-step strategy to being data driven, every should begin the process by making an information strategy and roadmap, additionally, instituting an analytics platform and data governance guidelines that involve the following steps:

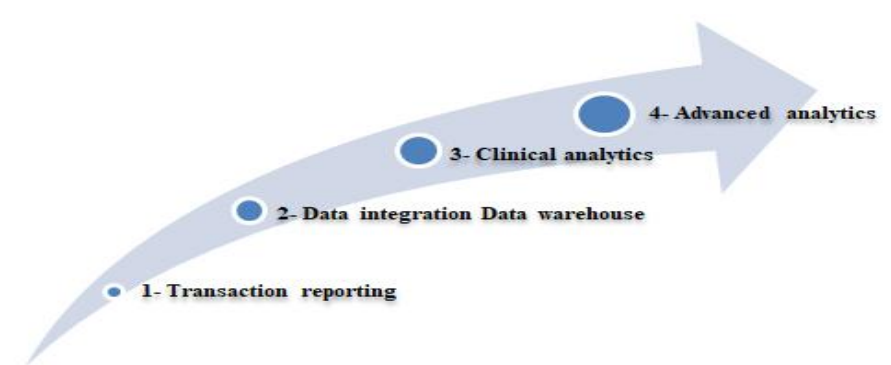

Figure 2. Important steps to becoming a data-driven health care organization

Table 3. Important steps to becoming a data-driven health care organization 
By executing these steps and laying the foundation to create valuable insights and change the manner in which health care is delivered, smart health care organizations can do as the following:

- Determining factors that can help decrease the growth of chronic diseases and development of diseases.

- Improving care for the elderly population whose health is particularly influenced by environmental and societal factors.

- Meeting patients and consumer needs and anticipation for better service and a more personalized experience through social and mobile engagement models.

- Achieving more understanding into patient results and smart health care.

- Meeting compliance and reporting requirements for results-based or responsible-care payment models.

\section{POTENTIAL SCENARIOS OF APPLYING BIG DATA ANALYTICS IN SMART HEALTH CARE [5, 22,28-29].}

The potential scenarios that lead to better smart health care outcomes from big data analytics can include the following cases:

- By analyzing patient characteristics and the expense and results of healthcare to recognize the most clinically and cost effective treatments and offer analysis and instruments, thereby impacting provider behavior.

- Applying sophisticated analyses to patient profiles -such as, segmentation and predictive modeling- to proactively recognize people who would benefit from preventative care or lifestyle changes.

- Large-scale disease profiling to recognize predictive events and supporting prevention initiatives.

- Gathering and distributing data on medical procedures, therefore, helping patients in determining the care protocols or regimens that offer the best worth.

- Determining, anticipating and limiting fraud by executing advanced analytic systems for fraud discovery and checking the accuracy and consistency of claims and executing much nearer to real-time, claim authorization.

- Making new income streams by collecting and synthesizing patient clinical records and claims data sets to give data and services to third parties, for instance, licensing data to help pharmaceutical companies in determining patients for inclusion in clinical trials.

- Numerous payers evolve and execute mobile apps that patients can use to administer their care, find providers, and improve their health. With analyses, payers can surveillance drug and treatment regimen adherence and

\begin{tabular}{|c|c|c|}
\hline 1- Transaction & - Spreadsheets & - What happened? \\
\hline $\begin{array}{l}\text { 1- Transaction } \\
\text { reporting }\end{array}$ & $\begin{array}{l}\text { - Spreadsheets } \\
\text { - Separate data } \\
\text { sources } \\
\text { - Manual } \\
\text { collation of data } \\
\text { - Basic reporting }\end{array}$ & $\begin{array}{l}\text { - What happened? } \\
\text { - How many, how often, } \\
\text { where? }\end{array}$ \\
\hline $\begin{array}{l}\text { 2- Data } \\
\text { integration } \\
\text { Data } \\
\text { warehouse }\end{array}$ & $\begin{array}{l}\text { - Unified data } \\
\text { sources } \\
\text { - Clinical data } \\
\text { repositories } \\
\text { - Departmental } \\
\text { data marts }\end{array}$ & $\begin{array}{l}\text { - What exactly is the } \\
\text { problem? } \\
\text { - What actions are } \\
\text { needed }\end{array}$ \\
\hline $\begin{array}{l}\text { 3- Clinical } \\
\text { analytics }\end{array}$ & $\begin{array}{l}\text { - Enterprise-wide } \\
\text { data } \\
\text { - Enterprise } \\
\text { analytics } \\
\text { - Clinical } \\
\text { outcomes } \\
\text { reporting }\end{array}$ & $\begin{array}{l}\text { - What is happening } \\
\text { across the organization? } \\
\text { - What is the } \\
\text { productivity / utilization } \\
\text { /efficiency for a certain } \\
\text { date range/set of } \\
\text { departments/work shift? }\end{array}$ \\
\hline $\begin{array}{l}\text { 4- Advanced } \\
\text { analytics }\end{array}$ & $\begin{array}{l}\text { - Evidence-based } \\
\text { medicine } \\
\text { - Personalized } \\
\text { health care } \\
\text { - Dynamic fraud } \\
\text { detection } \\
\text { - Patient and } \\
\text { member behavior }\end{array}$ & $\begin{array}{l}\text { - What could happen } \\
\text { next? What will happen } \\
\text { next if...? } \\
\text { - How can we achieve } \\
\text { the best outcome } \\
\text { including the effects of } \\
\text { variability? }\end{array}$ \\
\hline
\end{tabular}

identify trends that lead to individual and individual wellness benefits.

\section{STAKEHOLDERS: DIFFERENT GOALS [30]}

The health sector is one of the largest sectors in terms of funding, number of employees, variety of specializations, its impact on the rest of the sectors, as well as the importance of society as a whole, which is reflected in the size, diversity, speed and complexity of the in data generated in this sector as well as in the diversity of stakeholders in healthcare. With the generated big data. With the generated big data. Table 4. summarizes most important goals of stakeholder's beneficiaries of big data in the healthcare sector.

Table 4. Most important goals of stakeholders

\begin{tabular}{|c|c|}
\hline Stakeholders & Goals \\
\hline Patients & $\begin{array}{l}\text { - Regular utilization of technology } \\
\text { streaming seamlessly into their } \\
\text { healthcare. } \\
\text { - Easily comparing among health care } \\
\text { provider's levels. } \\
\text { - Customer-friendly service, and better } \\
\text { coordination among various providers. } \\
\text { - Ultimate goal means error-free, } \\
\text { effectiveness care and reasonable cost. }\end{array}$ \\
\hline $\begin{array}{l}\text { Health care } \\
\text { providers }\end{array}$ & $\begin{array}{l}\text { - Real-time access to patient, clinical } \\
\text { and other important data. } \\
\text { - Provide effective and error-free } \\
\text { healthcare, and technology be a }\end{array}$ \\
\hline
\end{tabular}




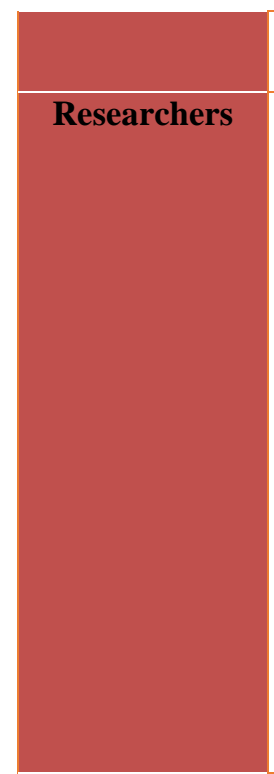

transparent tool, not an encumbrance. - Support improved decision-making.

- New tools to improve quality of

workflow for example, predictive modeling, statistical tools and algorithms to improve the design and result of experiments and provide a better understanding of how to evolve treatments that meet needs.

- Complete and correct data on patients, medicines and other related data on time.

- Analyzing illness patterns and tracking disease diffusion and transmission to improve public health monitoring, and speed reaction.

- Identify needs and foresee and forestall emergencies, particularly assist of lower income populations.

Pharma companies

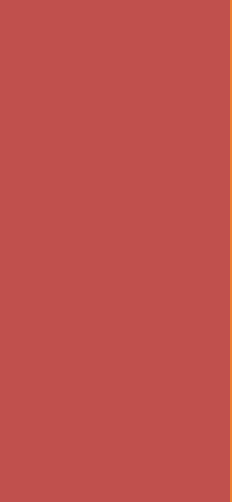

Medical

device

companies

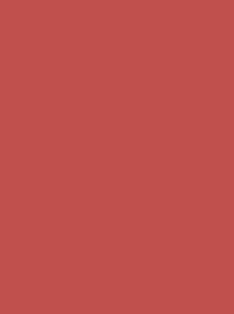

Payers

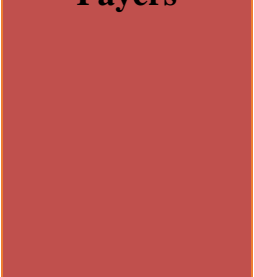

Governments
- Better understand the causes of diseases.

- Design more fruitful clinical trials to avoid failures.

- Analyzing clinical trials and patient records to recognize follow-on

indications and detect adverse impacts

before products arrive at market.

- Quicker improvement of more accurately targeted vaccines, for example choosing the yearly flu strains.

- Developing Pharmaceutical product,

to be Market more secure and more powerful drugs.

- Collecting data from hospital and

home devices for safety surveillance and adverse event expectation.

- Integrate data within old and new forms of personal data.

- Improving the performance of medical devices based on analysis of big data. to meet patients' needs and improve

health care by analyzing big data.

- Transforming from fee-for-service to pay-for-performance

- Use Big Data to help classify population hazard.

- Instruct them to more sustainable

business models for example, developing into health management, data analytics and API platforms. - Trying to diminish costs.

- Enforce regulations and growing the social value of data.

- Ameliorate the quality of health care by analyzing big data.

- Rising awareness of the significance of big data to improve the quality of
- Innovating modern medical devices

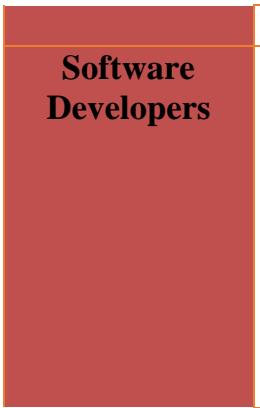

healthcare

- Opportunities to serve an huge and developing market in healthcare that

IT has already transformed.

- Developing systems to improve the performance of big data analytics systems.

- Facilitate using big data analytics by developing Application programming interface.

\section{RECOMMENDATIONS FOR ACHIEVE SMART HEALTH CARE [31-32]}

To effectively distinguish and execute big data solutions and get the value can achieve, health care organizations must dedicate time and resources to implement visioning and planning. This will lay foundation for strong implementation to make health care smarter and more sustainable. The recommendations for achieving the goals of smart health organizations include the following:

1- Standards: Developing standards for big data in healthcare to improve and facilitate its application and improve interoperability.

2- Education and training: Empower human capital to meet the developing requirement for a workforce capable of utilizing the potential of big data in healthcare.

3- Evaluating the different big data initiatives that can be deployed to meet overall organization goals, focusing initially on fast successes.

4- Governance of data access and utilize: Execute governance mechanisms to guarantee secure and fair access and use of big data for research in health.

5- Data sources: Expanding existing and explore new sources of big data in health and secure their quality and safety.

6- Transparency: Policy makers should embrace measures that raise transparency about real health information uses.

7- Funding and financial resources: Guarantee purposeful investment steered by the government and stakeholders to warrant cost-effectiveness and sustainability.

8- Lawful aspects and privacy regulations: Clarify and adjust existing legal and privacy regulation of big data in health.

9- Better educate citizens about privacy and security laws and use personal data in healthcare to build trust in use big data in healthcare.

\section{CONCLUSION}

Purpose big data analytics in health care is to promote healthy living and well-being for all people everywhere and at all ages. This study provided an overview big data analytics in health care, looked at how it is becoming a growing force in the changing health care landscape, and 
improved health care to become smarter and more sustainable. The study presented the key benefits and challenges of big data analysis in health care. and presented sources, types and tools that big data uses intelligent health care. Addition discussing scenarios analyzing big data smart healthcare and key steps in developing a data-driven health care organization, the study also looked at the various goals big data analysis by stakeholder's smart health care. Finally, the study suggested recommendations that can improve efficient use big data health care to be smarter and more sustainable.

\section{ACKNOWLEDGEMENT}

We would like to thank the Technical University of Berlin, Birzeit University and the Islamic university of Gaza for giving us the opportunity to use their available publication in this regard.

\section{REFERENCES}

[1] Raghupathi W: Data Mining in Health Care. In Health Care Informatics: Improving Efficiency and Productivity. Edited by Kudyba S. Taylor \& Francis; 2010:211-223.

[2] Frost \& Sullivan: Drowning in Big Data? Reducing Information TechnologyComplexities and Costs for Healthcare Organizations. http://www.emc.com/collateral/analystreports/frost-sullivan-reducing-information-

technologycomplexities-ar.pdf.

[3] Ikanow: Data Analytics for Healthcare: Creating Understanding from Big Data.http://info.ikanow.com/Portals/163225/docs/data-analyticsfor-healthcare.pdf.

[4] jStart: "How Big Data Analytics Reduced Medicaid Readmissions." A jStart CaseStudy; 2012. http://www01.ibm.com/software/ebusiness/jstart/portfolio/uncMedicaidCase Study.pdf.

[5] Knowledgent. (2013) : Big Data and Healthcare Payers. http://knowledgent.com/mediapage/insights/whitepaper/482.

[6] Marrynal .S., Premalatha .P. (2016). Application of Big Data Analytics in Health Care. Journal of Engineering Research and Application,ISSN : 2248-9622, Vol. 6, Issue 12, ( Part -2).

[7] Ristevski, B. and Chen, M. (2018). Big Data Analytics in Medicine and Healthcare. Journal of Integrative Bioinformatics, published by De Gruyter.

[8] Zhang, C., Ma, R., Li, Y., Wang, Y., Sun, S., and Yan, Z. (2017). Optimizing the Electronic Health Records through Big Data Analytics: A Knowledge based View. DOI 10.1109/ACCESS.2019.2939158, IEEE Access.

[9] Palanisamy, V. and Thirunavukarasu, R. (2017). Implications of big data analytics in developing healthcare frameworks - A review, Journal of King Saud University - Computer and Information Sciences.

[10] Muni Kumar, N. and Manjula, R. (2014). Role of Big Data Analytics in Rural Health Care - A Step Towards SvasthBharath, (IJCSIT) International Journal of Computer Science and Information Technologies, Vol. 5 (6), 7172-7178.

[11] Mauro, A., Greco, M. and Grimaldi, M. (2014). Grimaldi, what is big data? A consensual definition and a review of key research topics, 4th International Conference on Integrated Information.

[12] Gandomi, A. and Haider, M. (2015). Beyond the hype: big data concepts, methods, and analytics, Int. J. Inf. Manage. (35) 137-144.

[13] Halamka, J. (2014). Early experiences with big data at an academic medical center, Health Aff. (33) 1132-1138.
[14] Auffray, C., Balling, R., Barroso, I., et al. (2016). Making sense of big data in health research: towards an EU action plan. Genome Med, 8:71.

[15] James Manyika MC, Brown B, Bughin J, Dobbs R, Roxburgh C, Byers AH. Big data: The next frontier for innovation, competition, and productivity. (2011).

[16] Raghupathi, W. and Raghupathi, V. (2014). Big data analytics in healthcare: promise and potential. Health Information Science and Systems, BioMed Central, 2 (1), 10.1186/2047-2501-2-3. hal-01663474

[17] IHTT: Transforming Health Care through Big Data Strategies for leveraging big data in the health care industry; (2013). http://ihealthtran.com/wordpress/2013/03/iht\%C2\%B2releases-big-data-research-reportdownload-today/.

[18] Bernstein, S. (2014). The US big data report and fully utilizing big data within healthcare. eHealth Law and Policy. $1(4)$.

[19] Raghupathi, W. and Kesh, S. (2007). Interoperable electronic health records design: towards a service-oriented architecture. e-Service Journal, 5:39-57.

[20] European Commission. Report on the use of -omic technologies in the development of personalized medicine Brussels: European Commission, 2013.

[21] Klimek, P. Big Data, Complexity, und Gesundheit in Österreich. (n.d).

[22] IBM Software, White Paper. (2013). Data-driven healthcare organizationsuse big data analytics for big gains. http://slidepdf.com/reader/full/data-driven-healthcareorganizations-use-big-data-analytics-for-big-gains.

[23] Grant, R. M. (1996). Toward a knowledge-based theory of the firm, Strategic Management Journal, vol.17, no.2, pp.109122.

[24] Zack, M., McKeen, J. and Singh, S. (2009). Knowledge management and organizational performance: an exploratory analysis, Journal of Knowledge Management, vol. 13, no.6, pp. 392-409.

[25] Agarwal, R., Gao, G., DesRoches, C. and Jha, A. K. (2010). Research Commentary-The Digital Transformation of Healthcare: Current Status and the Road Ahead, Information Systems Research, vol. 21, no.4 no.pp.796-809.

[26] Kogut, B. and Zander, U. (1992). Knowledge of the Firm, Combinative Capabilities, and the Replication of Technology, Organization Science, vol. 3, no. 3, pp. 383-397.

[27] Fatt,QK. and Ramadas, A. (2018). The Usefulness and Challenges of Big Data in Healthcare. J HealthcCommun, Vol.3, No.2:21

[28] Savage, N. (2012). Digging for drug facts. Commun ACM, 55(10):11-13.

[29] Zenger, B. (2012). Can Big Data Solve Healthcare's Big Problems? HealthByte. http://www.equityhealthcare.com/docstor/EH\%20Blog\%20on\% 20Analytics.pdf.

[30] Feldman, B., Martin, E. and Skotnes, T. (2012). Big Data in Healthcare Hype and Hope, Business Development for Digital Health.

[31] Health IT Policy Committee: Privacy and Security Workgroup. (2015). HEALTH BIG DATA RECOMMENDATIONS. U.S.

[32] Habl, H., Renner, A., Bobek, J. and Laschkolnig, A. (2016). Study on Big Data in Public Health, Telemedicine and Healthcare, Final Report, European commission. ISBN 978-9279-63285-3. 


\section{Authors profile}

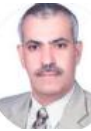
Tanta University of Egypt 1986, IT specialist in U.A.E University 1994 - 2012, M.S. from Islamic University of Gaza 2019 researcher in Smart city subjects, researcher by, Islamic University, Geography and GIS Department E-mail: abdelkhalek.alastal@gmail.com

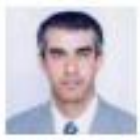

2Assistant Professor. Muain Qasem Jawabrah B.S and M.S. degrees from Politecnico Di Milano 1987 Inderizio Projetazione Architettonica Ph.D. in Architectural from (RWTH Aachen Germany) 1997. Recently Assistant professor of Architecture, Birzeit University, Palestine E-mail: mqasem@birzeit.edu

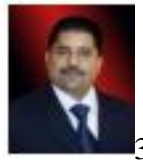

Associate Professor Dr. Read A. Salha B. S degrees from University of King Abdul Aziz 1984, M.S. from the Arab League University of Cairo1994, PhD in Geography and GIS from the Arab League University of Cairo 2003. Currently works as Associate Prof at Islamic University of Gaza since 18years, Faculty of Arts, Islamic University, Geography and GIS Department. Email: msalha@iugaza.edu.ps

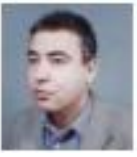

4 Professor Dr. Usama Ibrahim Badawy, B. S and M.S. degrees from Technical University of Berlin Architectural Departmernt1991. PhD in Urban Planning from Technical University of Berlin 1997 Former Professor of Architecture, Birzeit University, Engineering Department, works currently by the UN. E-mail: ubadawy@yahoo.com 